\title{
Prevalence and Effect Evaluation of FLT3 and NPM1 Mutations in Acute Myeloid Leukemia Patients in Eastern Algeria
}

\author{
Ouarda Sariyah AYACHI ${ }^{1}$, Mohamed Larbi REZGOUN ${ }^{1,2}$, Muge SAYITOGLU ${ }^{3}$, \\ Didem ALTINDIREK ${ }^{3}$, Yucel ERBILGIN ${ }^{3}$, Noureddine ABADI ${ }^{2}$, Dalila SATTA ${ }^{1,2}$ \\ ${ }^{1}$ University Constantine I, Laboratory of Biology and Molecular Genetics, Constantine, ALGERIA \\ ${ }^{2}$ University Ben-Badis, University Constantine III, Hospital Center, Laboratory of Biology and Genetic, \\ Constantine, ALGERIA \\ ${ }^{3}$ Istanbul University, Aziz Sancer Institute of Experimental Medicine, Department of Genetics, \\ Istanbul, TURKEY
}

\begin{abstract}
Fms-like tyrosine kinase 3 (FLT3) and Nucleophosmin1 (NPM1) mutations are the most common molecular variations in acute myeloid leukemia (AML) and have been associated with prognosis. The frequencies of FLT3, NPM1 mutations in the Algeria population remains unknown due to the lack of data related to this subject. Herein, we aim to investigate the prevalence of these mutations in our population and assess their prognosis impact. Adult AML patients $(n=60)$ were analyzed for FLT3-internal tandem duplication (ITD), D835Y point mutation and NPM1 exon12 mutations. FLT3-ITD was detected using polymerase chain reaction (PCR), D835Y mutation was detected by restriction fragment length polymorphism (PCR-RFLP) and NPM1 exon12 was detected by Sanger sequencing. The relation between the mutations and the clinical features of the patients was evaluated. FLT3 mutations were present in $11.6 \%$ and NPM1 mutations were observed in 15.09\% of AML patients. The most frequent NPM1 mutation type was the "type-A mutation" (87.5\%). Furthermore, a novel "indel" mutation was also detected in one patient. According to the statistical analysis results, FLT3mut group showed shorter survival time and poor response to the induction therapy, while NPM1 was a predictor of better prognosis in the absence of FLT3 mutations. Our results reveal that FLT3 and NPM1 mutations are less frequent in our population than reported in literature. Patients with isolated NPM1 and FLT3 mutation have different clinical features than those with combined mutations. NPM1 and FLT3 mutations can be used as prognostic factors in AML risk classification.
\end{abstract}

Keywords: Acute myeloid leukemia, FLT3, NPM1, Mutation, Prognosis

\section{INTRODUCTION}

Acute myeloid leukemia (AML) is an aggressive heterogeneous disorder of the hematopoietic stem cell arising from the bone marrow. It is the outcome of several transformations that affect the balance between cell proliferation, survival and differentiation resulting in the expansion of an abnormal clone of cells. ${ }^{1}$

The standard induction therapy for the AML patients is Anthracycline and Cytosine Arabinoside (Ara-C), introduced in 1960's and since then, ap- proximately $50-75 \%$ of the AML patients achieve remission. ${ }^{2}$ Despite the increase therapy response, almost half of AML patients develop relapse which is the most substantial challenge in the treatment of the disease. ${ }^{3,4}$

One or more cytogenetic abnormalities are found in approximately $55 \%$ of AML and these markers are used to stratify patients into favorable, intermediate and unfavorable risk groups. However, the stratification and the treatment decision for patients with normal karyotype show difficulties due to the clinical heterogeneity. 
Nowadays, many genetic and epigenetic mutations have been associated with AML: KIT, NPM1, FLT3, WT1, CEBPA, RAS, BAALC, MN1, DNMT3A, TET2, IDH. ${ }^{5}$

Among the many reported mutations, FLT3, NPM1 and CEBPA genes are associated with treatment response, especially secondary mutations that involve mainly FLT3 gene. ${ }^{6,7}$

FLT3 (Fms-like tyrosine kinase 3) belongs to the class III of the family tyrosine kinase receptors, is coded by a gene of 24 exons on the chromosome 13q12.2. This receptor plays important roles in the hematopoietic growth regulation of early progenitor cells[8]. The FLT3 receptor contains a N-terminal extracellular region consisting of five immunoglobulin-like domain, a juxtamembrane domain (JM) and an intracellular C-terminal region with a split kinase domain. ${ }^{9}$ Internal tandem duplication (ITD) in the juxtamembrane domain and missense point mutation in tyrosine kinase (TKD) domain are frequent abnormalities in AML patient.

The FLT3-ITD mutations are observed in approximately $25-30 \%$ of patients and FLT3-TKD alterations are presented in $5-10 \%$ patients with AML. ${ }^{10,11}$ These mutations cause overexpression or activation of the tyrosine kinase receptor. Furthermore, FLT3-ITD mutations seem to be associated with increased relapse risk and short overall survival time. ${ }^{12}$ On the other hand, FLT3-TKD mutations' prognosis impact has not been yet clearly defined.

NPM1(Nucleophosmin) is a phosphoprotein expressed at high levels in the granular region of the nucleus. ${ }^{13}$ NPM1 shuttles between both the nucleus and the cytoplasm, and plays various roles within the cell including the control of centrosome duplication, ribosomal assembly and regulation of the tumor suppressor ARF. ${ }^{14}$ NPM1 exon12 mutations occur in about $30-35 \%$ of adult AML and confer a favorable prognosis. ${ }^{15}$ AML with NPM1 mutations was recognized as a separate provisional entity in the latest World Health Organisation (WHO) classification. ${ }^{16}$

More than 55 unique mutations have been identified in exon12 of NPM17 but the most frequent ones are: TCTG (Type A) duplication at NM_002520.6(NPM1_v001)c.860_863dup, CATG (Type B) and CCTG (Type D) insertions at NM_002520.6(NPM1_v001) c.863_864 ${ }^{18,19}$, recently the -CTTG insertion in the position c.863_864 was defined as the fourth most common mutation of the NPM1 named as mutation I. ${ }^{20}$ These mutations can cause the elongation of the NPM1 phosphoprotein that leads to an aberrant cytoplasmic expression. ${ }^{15}$

NPM1 mutation analyses coupled with FLT3 mutation analysis have considerable clinical utility in directing AML therapy. Unfortunately, not all centers, especially in developing countries are well equipped for molecular studies. Herein, firstly we aimed to optimize the FLT3 and NPM1 mutation analysis in our hospital that received the majority of the Eastern Algerian population and then investigate the prevalence of FLT3 and NPM1 mutations in patients with AML and assess their impact on the prognosis of our population. Notably, as far as we know this is the first report of FLT3-NPM1 mutations in Algeria.

\section{PATIENTS AND METHODS}

\section{Patients:}

Newly diagnosed adult AML patients $(n=60)$ were admitted to the University Hospital Center of Constantine between 2015 and 2016 were included in this study. The diagnosis was established according to the French-American-British (FAB) criteria and patients received the standard induction therapy regimen $(3+7)$, according to the hematology service, the protocol consisted of Aracytine $3 \mathrm{~g} / \mathrm{m}^{2}$ $\times 2$ in intra venous for 3 days and Cerubidine 60-90 $\mathrm{mg} / \mathrm{m}^{2}$ then followed by bone marrow aspirates.

Complete Remission (CR) was defined as less than $5 \%$ of blast cells, neutrophil $>1.5 \times 10^{9} / \mathrm{L}$ and platelets $>100 \times 10^{9} / \mathrm{L}$ in the peripheral blood. And for the post-remission therapy (consolidation phase), the patients have received Ara-C $12 \mathrm{~g} / \mathrm{m}^{2}$ IV for 3 days. In total, patients can receive up to 4 courses of consolidation.

All patients were informed about the study and provided written informed consent.

\section{Nucleic Acid Isolation:}

Genomic DNA was extracted from peripheral blood leukocytes using non-organic solvent $(\mathrm{NaCl}$ methods $)^{21}$, DNA quality and concentration were 
evaluated with Nanodrop spectrophotometer (Thermo Scientific Nanodrop ${ }^{\circledR}$ 2000/2000c).

\section{Mutational Analysis:}

\section{Screening for Mutations of FLT3 Gene:}

The FLT3-ITD exon14-15 was amplified by PCR using with specific primers: $14 \mathrm{~F}: 5$ 'GCAATTTAGGTATGAAAGCCAGC-3',15R:5'CTTTCAGCATTTTGACGCA ACC-3', that covers the JM domain with a length of $389 \mathrm{bp}$. Reactions of $25 \mu \mathrm{l}$ contained $100 \mathrm{ng}$ of DNA, Buffer, dNTPs $(10 \mathrm{mM}), \mathrm{MgCl}_{2}(2.5 \mathrm{mM})$, primers $(10$ $\mathrm{mM}$ each), 1U of Taq polymerase (Fermentas ${ }^{\circledR}$ ). After an initial denaturation at $94^{\circ} \mathrm{C}$ for $4 \mathrm{~min}$, DNA was amplified in 35 cycles of $94^{\circ} \mathrm{C}$ for 30 sec, $56^{\circ} \mathrm{C}$ for $30 \mathrm{sec}, 72^{\circ} \mathrm{C}$ for $1 \mathrm{~min}$ and followed by final extension at $72^{\circ} \mathrm{C}$ for $10 \mathrm{~min}$. The PCR products were run on a $3 \%$ electrophoresis agarose gel stained with Ethidium bromide and visualized on a UV lamp. Samples showing additional PCR products longer than $389 \mathrm{bp}$ were considered as FLT3-ITD.

To detect FLT3 D835Y mutation, primers for the exon20 were used: 20F: 5'-GAACGTGCTTGTCAC-3', 20R: 5'-TCAAAAATGCACCACAGTGAG-3', covering a region of 195 bp. The PCR mixture was set up as mentioned above. The initial denaturation was at $94^{\circ} \mathrm{C}$ for $10 \mathrm{~min}$, the annealing was $95^{\circ} \mathrm{C}$ for $30 \mathrm{sec}, 57^{\circ} \mathrm{C}$ for $30 \mathrm{sec}$ and $72^{\circ} \mathrm{C}$ for $30 \mathrm{sec}$, for 35 cycles and the final extension at $72^{\circ} \mathrm{C}$. The amplified products were digested with EcoRV(Fermentas) $5 \mathrm{U} / \mu \mathrm{l}$ at $37^{\circ} \mathrm{C}$ overnight. The digested products were analyzed on a $4 \%$ agarose gel. The D835Y mutation is a GAT $>$ TAT substitution that hides the restriction sequence for EcoRV, so incomplete digestion indicates the presence of the mutation.

\section{Detection of NPM1 (exon12) Mutations:}

For the screening of the NPM1 mutations, we first amplified fragment of the exon 12 by PCR using the primers NPM1-F,5-TGATGTCTATGAAGTGTTGTGGTTCC-3' and NPM1-R5'- CTCTGCATTATAAAAAGGACAGCCAG-3', the reaction volume was $25 \mu \mathrm{l}$ containing: a Buffer, $\operatorname{dNTPs}(0.4$ $\mathrm{mM}), \mathrm{MgCl}_{2}(2.5 \mathrm{mM})$, primers (5 $\mathrm{mM}$ each), $1 \mathrm{U}$ of Taq polymerase(Fermentas $\left.{ }^{\circledR}\right)$ and DNA $75 \mathrm{ng}$.
The program used was: $95^{\circ} \mathrm{C}$ as initial denaturation for $10 \mathrm{~min}$ and $72^{\circ} \mathrm{C}$ as final extension for $10 \mathrm{~min}$. The number of cycles was 35 and in each one, there was $95^{\circ} \mathrm{C}$ for $30 \mathrm{sec}$ denaturation, $63^{\circ} \mathrm{C}$ for $30 \mathrm{sec}$ annealing and $72^{\circ} \mathrm{C}$ for $40 \mathrm{sec}$ extension. The PCR products were checked using an agarose gel, then the amplified products were purified by standard method then directly sequenced on a DNA sequencer (Applied Biosystem 3500/3500XL). CLC Genomic Workbench 3.6 (Quiagen Bioinformatics Germany) was used for Sanger Sequencing data analysis and the reference sequence of NPM1 (NCBI Gene ref 4869).

\section{Statistical Analysis:}

The Overall Survival (OS) was calculated from the date of diagnosis to the date of death. The EventFree Survival (EFS) was calculated from the date of diagnosis to the occurrence of an event (failure at remission, relapse, and death in first CR).

All our data were analyzed using: Chi-square test or Fisher's exact test, Student's t test, ANOVA test, Kaplan-Meier for assessing OS and the Log-rank test to evaluate difference in survival between the 2 groups with Confidence Interval (CI) 95\%. P values were considered significant if it was $<0.05$. All analyses were done using the SPSS ${ }^{\circledR}$ software V.21.

\section{RESULTS}

Among a cohort of 60 newly diagnosed AML patients, $57 \%$ were male, $43 \%$ were female. The sex ratio was 1.3 . The median age was 46 years [range 21-86 years] at diagnosis. The most common FAB subtype was M2 that presented $45 \%$, followed by LAM4 18\%. The clinical characteristics of our study population are presented in the Table1.

\section{FLT3 and NPM1 Mutations' Frequencies:}

FLT3mut was found in 7 out of the 60 adult AML cases (11.66\%). FLT3-ITD mutation was shown in 4 cases and FLT3-TKD mutation was screened in 3 cases, one patient had combination of both mutations (Figure1).

Fifty three patients were analyzed for exon 12 of NPM1, NPM1 mutations were found in eight 
International Journal of Hematology and Oncology

Table 1. Clinical and biological parameters of patients

\begin{tabular}{|c|c|}
\hline Variables & Values \\
\hline \multicolumn{2}{|l|}{ Age } \\
\hline median (min-max)years & $46(21-86)$ \\
\hline \multicolumn{2}{|l|}{ Gender } \\
\hline Male n (\%) & 34 (57\%) \\
\hline Female n (\%) & $26(43 \%)$ \\
\hline \multicolumn{2}{|l|}{ WBC (X109/L) } \\
\hline$<50$ n (\%) & $44(73.33 \%)$ \\
\hline$\geq 50$ n (\%) & $16(26.66 \%)$ \\
\hline Mean & 55.36 \\
\hline Median (min-max) & $17.05(0.19-970)$ \\
\hline \multicolumn{2}{|l|}{$\mathrm{Hb}(\mathrm{g} / \mathrm{dL})$} \\
\hline$<10 \mathrm{n}(\%)$ & 52 (86.66\%) \\
\hline$\geq 10$ n (\%) & 8 (13.33\%) \\
\hline Mean & 7,91 \\
\hline Median (min-max) & $7.7(3.4-13)$ \\
\hline \multicolumn{2}{|l|}{ Platelet count $\left(X 10^{9} / L\right)$} \\
\hline$<50 \mathrm{n}(\%)$ & 32 (53.33\%) \\
\hline$\geq 50$ n (\%) & $28(46.66 \%)$ \\
\hline Mean & 66.55 \\
\hline Median (min-max) & $36(3-407)$ \\
\hline \multicolumn{2}{|l|}{ BM Blasts (\%) } \\
\hline$<80 \%$ n (\%) & 27 (45\%) \\
\hline$\geq 80 \%$ n (\%) & $33(55 \%)$ \\
\hline Mean & 71.0 \\
\hline Median (min-max) & $81(16-99)$ \\
\hline
\end{tabular}

cases $(15.09 \%) .7$ cases $(87.5 \%)$ had Type A-TCTG duplication in position c.860_863, and one case had a unique mutation pattern that doesn't belong to the reported mutations c.869_873delGGAGGinsCTTTTTCCC (Figure2). Although most of the NPM1 mutations in AML are 4bp insertions after position 863 in the coding sequence, several mutations have been noted that have breakpoints a few bases downstream after position $869 . .^{15}$

\section{FLT3 and NPM1 Mutations' Characteristics and Clinical Significance:}

In the FLT3mut group, 4 were female and 3 were male, while in the NPM1 mutated group 5 were male and 3 female. The most frequent FAB subtype variety was $\mathrm{M} 2$ in both mutations. The mean WBC count was significantly lower in the FLT3mut than the FLT3wt (wild type) group $\left(28.32 \times 10^{9} / \mathrm{L}\right.$ vs. $\left.55.93 \times 10^{9} / \mathrm{L}\right)(\mathrm{p}=0.03)$. The mean platelets count was significantly lower in the FLT3mut group $\left(23.17 \times 10^{9} / \mathrm{L}\right.$ vs. $\left.71.7 \times 10^{9} / \mathrm{L}[\mathrm{p}=0.002]\right)$. As for the NPM1 mutations, there were no significant differences in biological and clinical characteristics between mutated and wt patients as it's shown in Table 2.

To analyze both mutations at the same time, we categorized our studied patients in four groups:

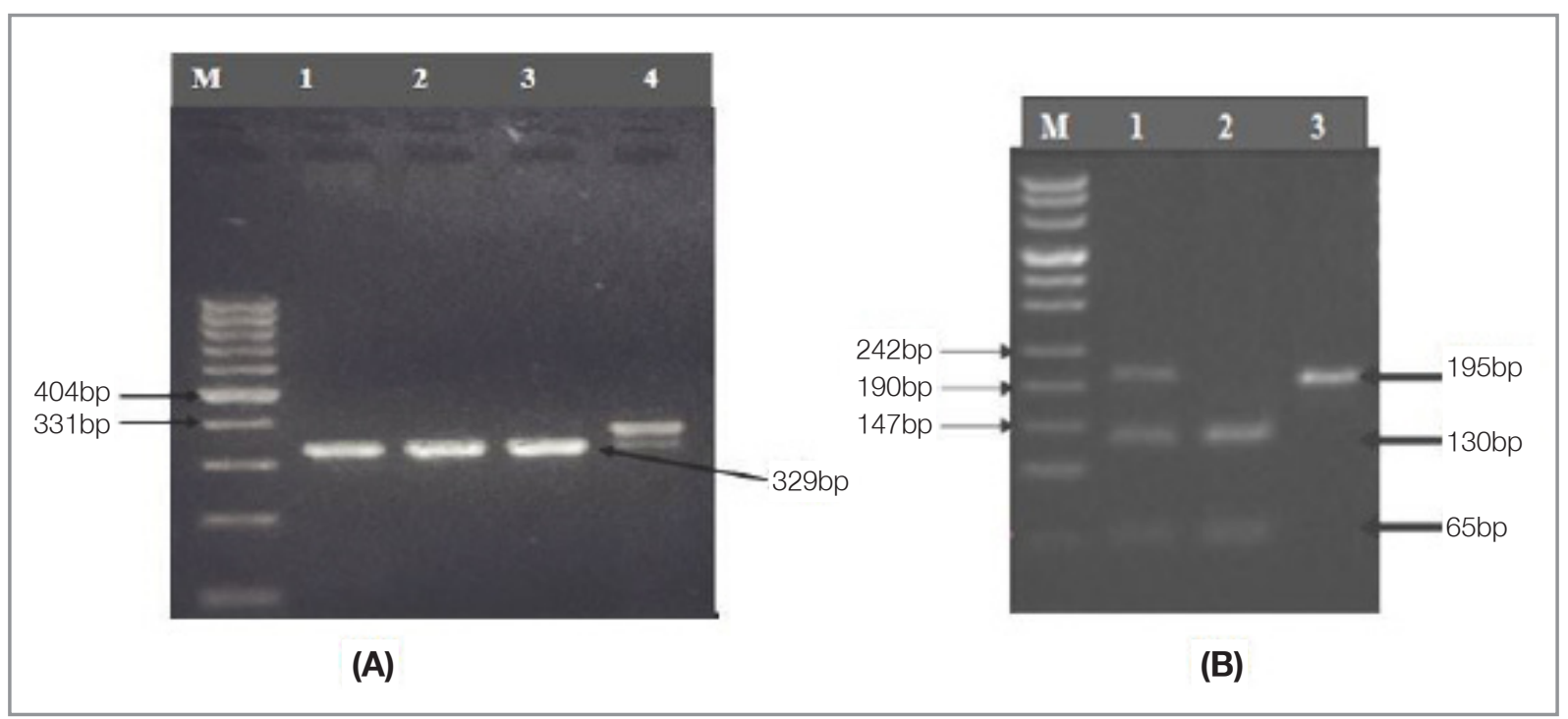

Figure 1. Detection of FLT3 mutations by PCR amplification. (A): Agarose gel profile of the FLT3-ITD. Lane M: size marker. Lanes: 1-2-3: are wt (329pb). Lane 4: Additional longer bands represent ITD. (B) EcoRV restriction of the PCR products of TKD. Lane M: size marker. Products not digested indicate that there is a point mutation. Lane 2: wt sample. Lane 1: TKD heterozygous sample. Lane 3: TKD homozygous sample. 
International Journal of Hematology and Oncology

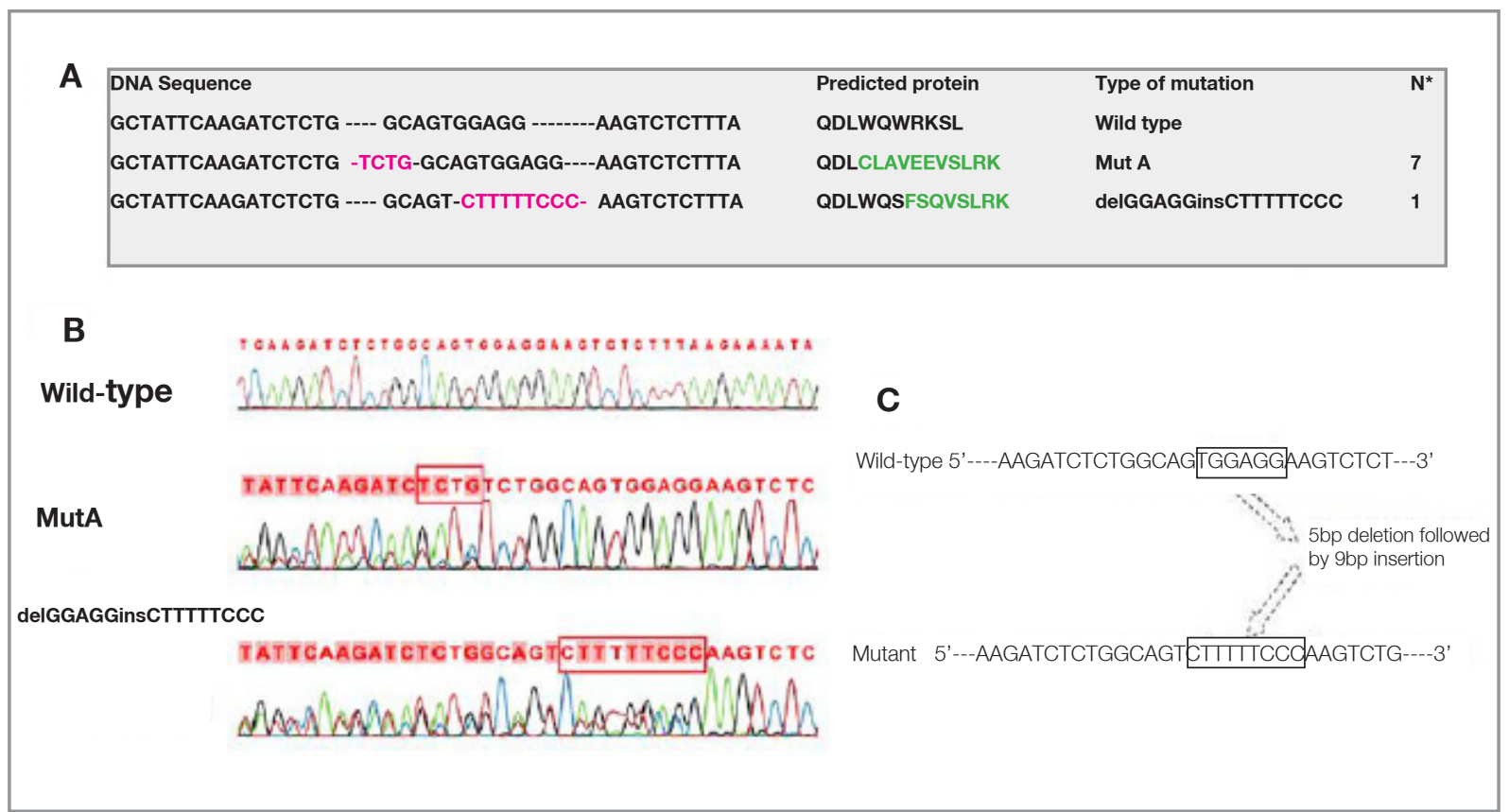

Figure 2. Mutations in NPM1 exon12. A) The mutated nucleotide and predicted amino acid sequence in NPM1 exon 12 found in the present study are shown in comparison with the wild-type sequence. Type of mutation (Mut A) is designated according to a previous report (Falini et.al.2005) ${ }^{15}$. Red indicates nucleotide insertions. Amino acids are given in single-letter code. Changed amino acids are indicated in green. B) Sanger sequencing images of wild type and mutated samples. C) Scheme of the mutagenesis with the deletion of 5bp and insertion of 9bp.

\begin{tabular}{|c|c|c|c|c|c|c|}
\hline & \multicolumn{3}{|c|}{ FLT3 mutations } & \multicolumn{3}{|c|}{ NPM1 mutations } \\
\hline & FLT3wt & $\mathrm{FLT3}^{+}$ & $p$ & NPM1wt & NPM1+ & $p$ \\
\hline Total & 53 & 7 & & 45 & 8 & \\
\hline Gender & & & 0.728 & & & 0.314 \\
\hline Male & 31 & 3 & & 25 & 5 & \\
\hline Female & 22 & 4 & & 20 & 3 & \\
\hline Age (years) & & & 0.58 & & & 0.151 \\
\hline Median & 46.7 & 51 & & 46 & 50 & \\
\hline Most common FAB & $43.0 / \%$ & $57.14 \%$ & 0.49 & $44.0 \%$ & $62.5 \%$ & 0.109 \\
\hline WBC (X10\%/L) & & & 0.03 & & & 0.084 \\
\hline Mean & 55.93 & 28.32 & & 66.81 & 23.86 & \\
\hline $\mathrm{Hb}(\mathrm{g} / \mathrm{dL})$ & & & 0.18 & & & 0.876 \\
\hline Mean & 7.77 & 8.21 & & 7.8 & 7.9 & \\
\hline Platelets (X10\%/L) & & & 0.002 & & & 0.196 \\
\hline Mean & 71.7 & 23.17 & & 86.52 & 56.75 & \\
\hline BM blast (\%) & & & 0.49 & & & 0.873 \\
\hline Mean & 71 & 74.83 & & 72.67 & 74.37 & \\
\hline Relapse & & & 0.674 & & & 0.045 \\
\hline Yes & 13 & 1 & & 10 & 0 & \\
\hline No & 40 & 6 & & 35 & 8 & \\
\hline Final Event & & & 0.02 & & & 0.403 \\
\hline Alive & 31 & 1 & & 24 & 3 & \\
\hline Deceased & 22 & 6 & & 21 & 5 & \\
\hline
\end{tabular}




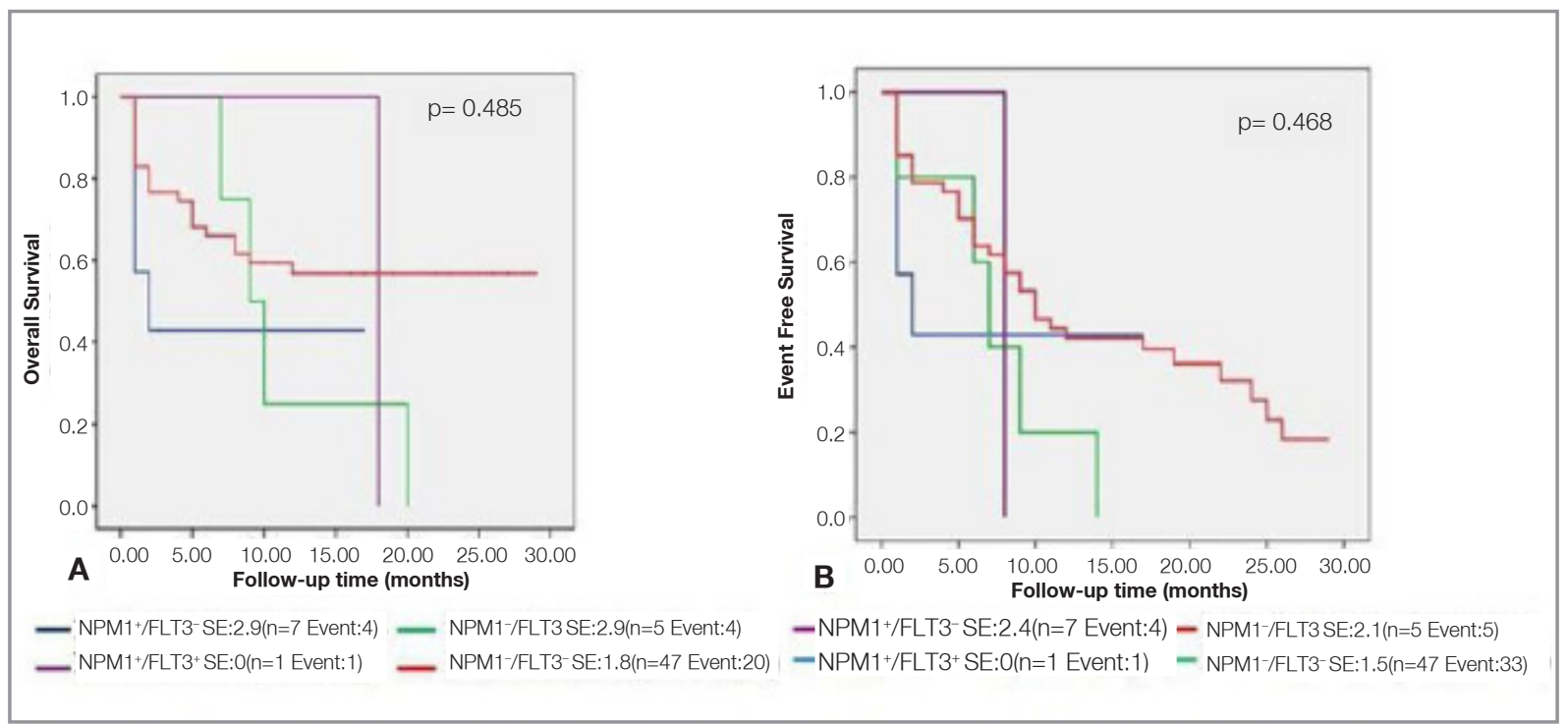

Figure 3. Kaplan-Meir analysis of the (A) OS, and (B) EFS of AML patients according to the FLT3 and NPM1 mutations

$\mathrm{NPM}^{+} / \mathrm{FLT}^{-}{ }^{-}, \quad \mathrm{NPM}^{-} / \mathrm{FLT}^{+}, \quad \mathrm{NPM}^{+} / \mathrm{FLT}^{+}$, $\mathrm{NPM}^{-/ \mathrm{FLT}^{-}}{ }^{-} \mathrm{NPM}^{+} / \mathrm{FLT3}^{-}$group showed an incidence of $11 \%$, while $\mathrm{NPM}^{-} / \mathrm{FLT}^{+}$group was $10 \%$. One patient $(2 \%)$ had both mutations $\left(\mathrm{NPM}^{+} / \mathrm{FLT}^{+}\right)$and $77 \%$ were negative for both mutations (NPM1-/FLT3-). Table 3 shows the clinical baselines between these groups.

\section{Response to Induction Therapy:}

Looking at each gene separately, the mortality rate in the FLT3 mutated group was significantly higher than the FLT3wt group ( $\mathrm{p}=0.02$ ), while, the relapse rate in the NPM1wt group was significantly lower than the mutated group $(\mathrm{p}=0.046)$ in Table 2 .

When the two mutations were analyzed simultaneously, the higher survival rate was observed in the NPM1-/FLT3 ${ }^{-}$group (58.69\%) and the $\mathrm{NPM}^{+}{ }^{+}$ FLT3 $^{-}(42.85 \%)$, both of the $\mathrm{NPM}^{+} / \mathrm{FLT}^{+}$and NPM1/- FLT3 $^{+}$patients were deceased. When compared, the survival rate of the group $\mathrm{NPM}^{-1}$ $\mathrm{FLT}^{+}$and the group $\mathrm{NPM}^{+} / \mathrm{FLT}^{-}$, it was statistically significant $(\mathrm{p}=0.022)$ indicating the positive effect of the NPM1 mutations on the prognosis. In term of relapse status among the four groups the FLT3-/NPM1- group has a higher percentage $(28.26 \%)$ which might be the reason of statistically significant score $(\mathrm{p}=0.047)$ in Table 3 .
Multivariate Cox regression analysis that evaluated the mutation status, age, WBC count and BM blast percentage showed that these factors were independent for achieving CR. (Data not shown).

\section{Survival Analysis:}

The median follow-up time of our population was 13 months [1-29 months]. The global survival rate was $51.66 \%$, among them $30 \%$ achieved complete remission.

The mean OS of all AML patients was 16.8 months and the mean EFS was 13.2 months. The mean OS was 12.8 months for the patients with the FLT3mut vs. 17.5 months for those without the mutation and the mean EFS was 9 months for the FLT3 mutation positive group, whereas it was 13.7 months for the FLT3wt .

On another hand, the mean OS and EFS for the NPM1mut group were 9.88 months and 8.77 months respectively and they were 12.33 months and 11.25 months for the NPM1wt (Figure 3).

\section{DISCUSSION}

In the present study, we determined the incidence of FLT3 and NPM1 exon12 mutations within the adult AML cohort, detected a novel complex mutation in NPM1 gene and described the biological characteristics and clinical features of these pa- 
International Journal of Hematology and Oncology

\begin{tabular}{|c|c|c|c|c|c|}
\hline Clinical features & NPM1 ${ }^{+} /$FLT3 $^{-}$ & NPM1 ${ }^{-} /$FLT3 $^{+}$ & NPM1+/FLT3 ${ }^{+}$ & NPM1 ${ }^{-} /$FLT3 $^{-}$ & $p$-value \\
\hline Sex & & & & & 0.498 \\
\hline Male & 5 & 3 & 0 & 26 & \\
\hline Female & 2 & 3 & 1 & 20 & \\
\hline Age & & & & & 0.56 \\
\hline Median & 54.14 & 45.4 & 51 & 45.19 & \\
\hline WBC (X10\%/L) & & & & & 0.846 \\
\hline Mean & 24.42 & 31.65 & 20 & 65.92 & \\
\hline $\mathrm{Hb}(\mathrm{g} / \mathrm{dL})$ & & & & & 0.839 \\
\hline Mean & 7.72 & 7.94 & 9.6 & 7.78 & \\
\hline Platelets (X10\%/L) & & & & & 0.389 \\
\hline Mean & 61.28 & 22.4 & 25 & 90.1 & \\
\hline BM blasts (\%) & & & & & 0.619 \\
\hline Mean & 78.28 & 80.4 & 47 & 70.57 & \\
\hline Relapse & & & & & 0.047 \\
\hline Yes & 0 & 1 & 0 & 13 & \\
\hline No & 7 & 5 & 1 & 33 & \\
\hline Final Event & & & & & 0.022 \\
\hline Alive & 3 & 1 & 0 & 28 & \\
\hline Deceased & 4 & 5 & 1 & 18 & \\
\hline
\end{tabular}

tients and estimated their prognosis significance in the Algerian population.

Constitutive activations of FLT3 (ITD and D835Y) were found in $11.6 \%$ of our cohort, the frequency is lower than the other studies (20-35\%). ${ }^{10,22}$ FLT3ITD presented $6.6 \%$, this frequency is low when compared to the previous reports. ${ }^{23,24}$ It has been stated that the lower frequencies of FLT3-ITD are observed in the Asian populations (19.1\%) compared to Western countries $(20-30 \%) .^{25,26}$ FLT3D835Y was found in 5\% (3 of 60) of our AML patients which is in agreement to what was expected $5-10 \% .^{27,28}$

Similar to the FLT3-ITD's results, we observed a lower frequency of NPM1 mutations (15.09\%) compared to previous studies ${ }^{15,29}$, type A mutation was the most frequent one, our findings confirmed the report made by Falini and coworkers. ${ }^{15}$ On another hand, the novel mutation was different from the 4bp insertions usually found in the NPM1 exon12 mutations and downstream the position c.860_863.
The disparity in FLT3-ITD and NPM1 mutations' frequencies between our study and the others may be related to the presence of racial/ ethnic variation in susceptibility to these mutations or the number of cases involved in each study. However, in spite of the neighborhood between Algerian and Moroccan population, the frequencies of the FLT3-ITD mutation reported in Morocco (18\%) were relatively higher than found in our study. ${ }^{30}$ These findings should be discussed within the context of lack of karyotype data which is remains the most important prognostic factor. However AML with normal karyotypes (NK-AML), which represent 40\%-50\% of AMLs, vary in term of prognosis.

The incidence of FLT3-ITD mutations occurs in the NPM1 mut group more than the NPM1wt group $(14.28 \%$ vs. $6.6 \%)$, which confirmed that NPM1 mutations are the primary aberrations that precede the acquisition of FLT3-ITD and explained the increased frequency of FLT3-ITD in NPM1mut cases. $^{31}$ 
NPM1 and FLT3 mutations increase in frequency as the population's age increases with a median age 51 and 50 years for the FLT3mut and NPM1+ respectively. These results were similar to what was reported before. ${ }^{32,33}$ The age factor also may explain the lower frequencies of the mutations given the fact that we had a considerably younger cohort with the median age 46 years at diagnosis.

M2 was the most common subtype within patients carrying the FLT3 and NPM1 mutations, these results are similar to several studies ${ }^{23,32}$, but are in contrast with others. ${ }^{34,35}$ Also, no mutations were found in patients with M3 subtype, which is consistent with the findings of Thiede et al. ${ }^{29}$, additionally, Veerhak et al. ${ }^{36}$ have registered a lower frequency of NPM1 mutations in M3 subtype.

The WBC count was significantly higher in the FLT3wt and NPM1wt patients than those with the mutations; these results were similar to other reports $^{34,37}$ and in disagreement with others. ${ }^{3,35}$

Interestingly, the NPM1 mutated group was associated with higher platelets count unlike the FLT 3 mut group which is in agreement with a study made by Hsu and Yung who showed that the blast cells with the NPM1 mutation can acquire a certain capacity for the differentiation of the thrombocytes. ${ }^{38}$

Another point that could have been informative is the evaluation of level changes of FLT3 ligand in peripheral blood through the course of AML patients. In fact, Şahin et al. have demonstrated that there was a reverse relationship between diagnostic and remission WBC count and FLT3 ligand levels, also, that FLT3 receptor inhibition during the induction chemotherapy causes a compensative ligand overexpression. ${ }^{39}$

Regarding the response to the treatment, only $30 \%$ of our patients achieved complete remission which is lower than other reports. ${ }^{34,40}$

Among the FLT3mut positive patients, no one achieved the CR. Also, the FLT3 mutations had a negative impact on survival $(\mathrm{p}=0.02)$, which comes in confirmation to what was concluded before about the fact that FLT3 mutation is a worse prognosis factor that significantly reduces the survival. ${ }^{12,23,41}$
Additionally, patients with FLT3-TKD are reported to have favorable clinical outcome than those carrying the FLT3-ITD mutation ${ }^{42}$, but the mortality rate of the FLT3-TKD patients in our cohort was $100 \%$, which suggest that these patients may had other alterations or environmental factors that had a negative effect on their prognosis.

Clinical impact of NPM1 different mutations is still not clear, some studies reported no differences regarding CR, OS and EFS between patients with type A mutations and non-type $\mathrm{A}^{43}$ while others observed a lower OS and EFS in patients with type A mutations compared to those with non-type A mutation. ${ }^{44}$ In our case, the patient with the novel mutation achieved complete remission with no resistance to the disease or relapse.

Unlike previous reports that demonstrated that NPM1 mutations were associated with a good prognosis ${ }^{15,40,45,46}$, the presence of NPM1 in our cohort didn't show any improvement in term of OS and EFS compared to the NPM1wt, nevertheless, CR rate of patients carrying the NPM1 mutations was higher than those with FLT3 mutations.

Therefore, when we assessed the prognosis impact according to the FLT3 and NPM1 mutations' status together, we observed that the relapse rate was significantly lower in the

$\mathrm{NPM}^{+} / \mathrm{FLT3}^{-}$group and the mortality rate was significantly higher in the NPM1-/FLT3 ${ }^{+}$and the double mutated group. Similar to our results, other studies have shown that NPM1 mutations in the absence of FLT3 mutations (NPM1 ${ }^{+} / \mathrm{FLT}^{-}$) are sign of favorable prognosis in terms of higher $\mathrm{CR}$, OS and EFS, while the double mutated patients $\left(\mathrm{NPM}^{+} / \mathrm{FLT}^{+}\right)$have the worst $\mathrm{CR}$ rate and $\mathrm{NPM}^{-/} / \mathrm{FLT}^{+}{ }^{+}$patients have the lowest OS and EFS. ${ }^{47,48}$

AML is often related to cytogenetic abnormalities and aberrant gene expression that are of great importance for clinical management. Current guidelines for the diagnosis of AML take into account several biomarkers that can be detected in peripheral blood like FLT3, NPM1, CEBPA and KIT genes mutations and cytogenetic results such as $\mathrm{t}(15 ; 17)$, $\mathrm{t}(8 ; 21)$. In addition, next-generation sequencing techniques have shown that the epigenetic profile of AML patients can act as a biomarker and cor- 
relating clinical outcome with DNA methylation status. Moreover, proteomic analysis is becoming a significant tool in the study of AML like ubiquitin-like modifier activating enzyme 1 (UBA1) and isoform 1 of Fibrinogen alpha chain precursor (FIBA) that are indicators of AML status [49]. The combination of these biomarkers will help to generate a more comprehensive picture of the underlying pathophysiological processes involved in the disease and therefore will lead to significantly improve the diagnosis, prognosis or monitoring of acute myeloid leukemia, as well as facilitating treatment decisions.

There were some limitations in this study, starting with the small sample size, which can be evident when we analyze the cohort in subgroups. Another one is the lack of available karyotypes in almost half of the cohort, which didn't allow us to stratify our patients.

In conclusion, we have described a novel complex (indel) mutation of the NPM1 gene in one patient and our results revealed that FLT3 and NPM1 mutations are less frequent in our population. The detected mutation c.869_873delGGAGGinsCTTTTTCCC in NPM1 gene is unique and different from all previously reported mutations. Additionally, our preliminary results suggest that the presence of FLT3 mutations had a negative impact on survival. Taken together, these data indicate that NPM1 mutations might have had better prognosis in the absence of FLT3 mutations, but the limited sample size of our cohort did not allow us to have any definite conclusion. Hence further studies with a large cohort need to be done to confirm that.

\section{Acknowledgements:}

We would like to thank the staff of the hematology service at University Hospital Center of Constantine for all the help they provided in this study.

\section{REFERENCES}

1. Murati A, Brecqueville M, Devillier R, et al. Myeloid malignancies: mutations, models and management. BMC Cancer 12: 304, 2012.

2. Rowe JM, Tallman MS. Intensifying induction therapy in acute myeloid leukemia: has a new standard of care emerged? Blood 90: 2121-2126, 1997.
3. Kottaridis PD, Gale RE, Linch DC. Prognostic implications of the presence of FLT3 mutations in patients with acute myeloid leukemia. Leuk Lymphoma 44: 905-913, 2003.

4. Meshinchi S, Smith FO, Arceci RJ. Prognostic factors and risk-based therapy in pediatric acute myeloid leukemia. Curr Oncol Rep 5: 489-497, 2003.

5. Dombret H. Gene mutation and AML pathogenesis. Blood 118: 5366-5367, 2011.

6. Grimwade D, Walker H, Oliver F, et al. The importance of diagnostic cytogenetics on outcome in AML: analysis of 1,612 patients entered into the MRC AML 10 trial. The Medical Research Council Adult and Children's Leukaemia Working Parties. Blood 92: 2322-2333, 1998.

7. Khan I, Altman JK, Licht JD. New strategies in acute myeloid leukemia: redefining prognostic markers to guide therapy. Clin Cancer Res 18: 5163-5171, 2012.

8. Meshinchi S, Appelbaum FR. Structural and functional alterations of FLT3 in acute myeloid leukemia. Clin Cancer Res 15: 4263-4269, 2009.

9. Agnès F, Shamoon B, Dina C,et al. Genomic structure of the downstream part of the human FLT3 gene: exon/intron structure conservation among genes encoding receptor tyrosine kinases (RTK) of subclass III. Gene 145: 283-288, 1994.

10. Papaemmanuil E, Gerstung M, Bullinger L, et al. Genomic Classification and Prognosis in Acute Myeloid Leukemia. N Engl J Med 374: 2209-2221, 2016.

11. Yamamoto $\mathrm{Y}$, Kiyoi $\mathrm{H}$, Nakano $\mathrm{Y}$, et al. Activating mutation of D835 within the activation loop of FLT3 in human hematologic malignancies. Blood 97: 2434-2439, 2001.

12. Gale RE, Green C, Allen C, et al. The impact of FLT3 internal tandem duplication mutant level, number, size, and interaction with NPM1 mutations in a large cohort of young adult patients with acute myeloid leukemia. Blood 111: 2776-2784, 2008.

13. Dalenc F, Drouet J, Ader I, et al. Increased expression of a $\mathrm{COOH}$-truncated nucleophosmin resulting from alternative splicing is associated with cellular resistance to ionizing radiation in HeLa cells. Int J Cancer 100: 662-668, 2002.

14. Garzon R, Garofalo M, Martelli MP, et al. Distinctive microRNA signature of acute myeloid leukemia bearing cytoplasmic mutated nucleophosmin. Proc Natl Acad Sci USA 105: 3945-3950, 2008.

15. Falini B, Mecucci C, Tiacci E, et al. Cytoplasmic nucleophosmin in acute myelogenous leukemia with a normal karyotype. N Engl J Med 352:254-266, 2005.

16. Arber DA, Orazi A, Hasserjian R, et al. The 2016 revision to the World Health Organization classification of myeloid neoplasms and acute leukemia. Blood 127: 2391-2405, 2016.

17. Heath EM, Chan SM, Minden MD, et al. Biological and clinical consequences of NPM1 mutations in AML. Leukemia 31: 798-807, 2017. 
18. Döhner K, Schlenk RF, Habdank M, et al. Mutant nucleophosmin (NPM1) predicts favorable prognosis in younger adults with acute myeloid leukemia and normal cytogenetics: interaction with other gene mutations. Blood 106: 37403746, 2005.

19. Schnittger S, Kern W, Tschulik C, et al. Minimal residual disease levels assessed by NPM1 mutation-specific RQ-PCR provide important prognostic information in AML. Blood 114: 2220-2231, 2009

20. Jeziskova I, Semerad L, Dvorakova D, et al. Novel complex mutation in NPM1 gene in patient with acute myeloid leukemia. Leuk Lymphoma 58: 746-748, 2017.

21. Miller SA, Dykes DD, Polesky HF. A simple salting out procedure for extracting DNA from human nucleated cells. Nucleic Acids Res 16: 1215, 1988.

22. Levis M. FLT3 mutations in acute myeloid leukemia: what is the best approach in 2013? Hematology Am Soc Hematol Educ Program 2013: 220-226, 2013.

23. Cuervo-Sierra J, Jaime-Pérez JC, Martínez-Hernández RA, et al. Prevalence and Clinical Significance of FLT3 Mutation Status in Acute Myeloid Leukemia Patients: A Multicenter Study. Archives of Medical Research 47: 172-179, 2016.

24. Al-Mawali A, Gillis D, Lewis I. Characteristics and Prognosis of Adult Acute Myeloid Leukemia with Internal Tandem Duplication in the FLT3 Gene. Oman Med J 28: 432-440, 2013.

25. Kiyoi H, Naoe T. FLT3 in Human Hematologic Malignancies. Leukemia \& Lymphoma 43: 1541-1547, 2002.

26. Ahmad F, Mandava S, Das BR. Analysis of FLT3-ITD and FLT3-Asp835 Mutations in de novo Acute Myeloid Leukemia: Evaluation of Incidence, Distribution Pattern, Correlation with Cytogenetics and Characterization of Internal Tandem Duplication from Indian Population. Cancer Investigation 28: 6373, 2010.

27. Kiyoi H, Naoe T. FLT3 mutations in acute myeloid leukemia. Methods Mol Med 125: 189-197, 2006.

28. Mead AJ, Linch DC, Hills RK, et al. FLT3 tyrosine kinase domain mutations are biologically distinct from and have a significantly more favorable prognosis than FLT3 internal tandem duplications in patients with acute myeloid leukemia. Blood 110: 1262-1270, 2007.

29. Thiede C, Koch S, Creutzig E, et al. Prevalence and prognostic impact of NPM1 mutations in 1485 adult patients with acute myeloid leukemia (AML). Blood 107: 4011-4020, 2006.

30. Dehbi H, Kassogue $Y$, Nasserddine S, et al. FLT3-ITD Incidence and FLT-D835 Mutations in Acute Myeloid Leukemia Patients with Normal Karyotype in Morocco: A Preliminary Study. Middle East Journal of Cancer 4: 1-5, 2013.

31. Palmisano M, Grafone T, Ottaviani E, et al. NPM1 mutations are more stable than FLT3 mutations during the course of disease in patients with acute myeloid leukemia. Haematologica 92: 1268-1269, 2007.
32. Jeon $\mathrm{Y}$, Seo SW, Park S, et al. Identification of Two Novel NPM1 Mutations in Patients with Acute Myeloid Leukemia. Ann Lab Med 33: 60-64, 2013.

33. Loghavi S, Zuo Z, Ravandi F, et al. Clinical features of De Novo acute myeloid leukemia with concurrent DNMT3A, FLT3 and NPM1 mutations. J Hematol Oncol 7: 74, 2014.

34. Blau O, Berenstein R, Sindram A, et al. Molecular analysis of different FLT3-ITD mutations in acute myeloid leukemia. Leuk Lymphoma 54: 145-152, 2013.

35. Gou H, Zhou J, Ye Y, et al. The prevalence and clinical profiles of FLT3-ITD, FLT3-TKD, NPM1, C-KIT, DNMT3A, and CEBPA mutations in a cohort of patients with de novo acute myeloid leukemia from southwest China. Tumour Biol 37: 7357-7370, 2016.

36. Verhaak RGW. Mutations in nucleophosmin (NPM1) in acute myeloid leukemia (AML): association with other gene abnormalities and previously established gene expression signatures and their favorable prognostic significance. Blood 106: 3747-3754, 2005.

37. Rezaei N, Arandi N, Valibeigi B, et al. FMS-Like Tyrosine Kinase 3 (FLT3) and Nucleophosmin 1 (NPM1) in Iranian Adult Acute Myeloid Leukemia Patients with Normal Karyotypes: Mutation Status and Clinical and Laboratory Characteristics. Turk J Haematol 34: 300-306, 2017.

38. Hsu CY, Yung BYM. Involvement of nucleophosmin/B23 in TPA-induced megakaryocytic differentiation of K562 cells. Br J Cancer 89: 1320-1326, 2003.

39. Sahin M, Haznedaroglu IC, Ozbalci D. Peripheral FLT-3 ligand levels as a pathobiological parameter duringthe clinical course of acute myeloid leukemia. Turk J Med Sci 46: 18891893, 2016.

40. Becker H, Marcucci G, Maharry K, et al. Favorable Prognostic Impact of NPM1 Mutations in Older Patients With Cytogenetically Normal De Novo Acute Myeloid Leukemia and Associated Gene- and MicroRNA-Expression Signatures: A Cancer and Leukemia Group B Study. J Clin Oncol 28: 596-604, 2010.

41. Yanada M, Matsuo K, Suzuki T, et al. Prognostic significance of FLT3 internal tandem duplication and tyrosine kinase domain mutations for acute myeloid leukemia: a meta-analysis. Leukemia 19: 1345-1349, 2005.

42. Li W, Zhang L, Huang L, Mi $Y$, et al. Meta-analysis for the potential application of FLT3-TKD mutations as prognostic indicator in non-promyelocytic AML. Leuk Res 36: 186-191, 2012.

43. Pastore F, Greif PA, Schneider S, et al. The NPM1 Mutation Type Has No Impact on Survival in Cytogenetically Normal AML. PLoS One 9:e1097592014. doi: 10.1371/journal. pone.0109759.

44. Alpermann T, Schnittger S, Eder C, et al. Molecular subtypes of NPM1 mutations have different clinical profiles, specific patterns of accompanying molecular mutations and varying outcomes in intermediate risk acute myeloid leukemia. 
Haematologica 101: e55-8, 2016. doi: 10.3324/haematol.2015.133819.

45. Verhaak RGW, Goudswaard CS, van Putten W, et al. Mutations in nucleophosmin (NPM1) in acute myeloid leukemia (AML): association with other gene abnormalities and previously established gene expression signatures and their favorable prognostic significance. Blood 106: 3747-3754,2005.

46. Thiede C, Steudel C, Mohr B, et al. Analysis of FLT3-activating mutations in 979 patients with acute myelogenous leukemia: association with $\mathrm{FAB}$ subtypes and identification of subgroups with poor prognosis. Blood 99: 4326-4335, 2002.

47. Konoplev S, Huang X, Drabkin HA, et al. Cytoplasmic Localization of Nucleophosmin in Bone Marrow Blasts of Acute Myeloid Leukemia Patients is not Completely Concordant with NPM1 Mutation and is not Predictive of Prognosis. Cancer 115: 4737-4744, 2009.

48. Mullighan CG, Kennedy A, Zhou X, et al. Pediatric acute myeloid leukemia with NPM1 mutations is characterized by a gene expression profile with dysregulated HOX gene expression distinct from MLL-rearranged leukemias. Leukemia 21: 2000-2009, 2007.

49. Bai J, He A, Zhang W, et al. Potential biomarkers for adult acute myeloid leukemia minimal residual disease assessment searched by serum peptidome profiling. Proteome Sci 11: 39, 2013.

\section{Correspondence:}

Ouarda Sariyah AYACHI

University of Mentouri Brothers- Constantine

Faculty of Nature and Life Sciences

Department of Animal Biology

P.O. Box, 325 Ain El Bey Way,

25017 CONSTANTINE / ALGERIA

Tel: +213555712873

e-mail: sariyah_ayachi@umc.edu.dz 